\title{
Produção de conhecimento no campo da Arte em tempos de isolamento social
}

2020, ano atípico. Pessoas amedrontadas pela doença e em isolamento social, o que contribuiu para o desemprego, estagnação na produção da economia, da cultura e porque não, da produção cientifica das Artes em nosso país. A crise de saúde se traduziu em crise econômica em todo o mundo. Comprometida com a ciência e o conhecimento, a ARJ - Art Research Journal/Revista de Pesquisa em Artes dá continuidade às suas atividades e publica no seu v. 7, n. 2, o dossiê Perspectivas multidisciplinares no campo da Arte, com artigos que refletem este enfoque.

Em "Estado de prontidão: pesquisa performativa e colaboração nos processos de criação interartística em 'Converse'”, Lia Günther Sfoggia, Guilherme Bertissolo e Luciane Cardassi descrevem e refletem sobre os processos de uma criação interartística colaborativa, a partir da pesquisa performativa, explorando o conceito de estado de prontidão no contexto da Capoeira Regional na Fundação Mestre Bimba. Os autores também sugerem que o desdobramento dos processos de construção de sentido nas diferentes linguagens possa acontecer pela perspectiva da cognição incorporada.

Dando continuidade às interfaces entre as perspectivas multidisciplinares no campo da arte, Luciane R. N. Garcez no artigo intitulado "Fragmentos de um noturno: interlocuções e história em Paulo Gaiad", apresenta a análise minuciosa de uma série do artista visual Gaiad e sua relação com a peça para piano Noturno, do compositor e pianista Alberto Andrés Heller. Gaiad fala dessa música visualmente, criando um espaço de intersecção entre as artes, de intertextualidade, que se torna "algo entre instalação e música, visualidade e sonoridade" ( $p$. 20). A autora assim, discute o caráter híbrido, interdisciplinar que marca o corpus poético de Gaiad de uma forma muito peculiar e pessoal. Ao trabalhar na incerteza, sem se fixar em resultados pré-estabelecidos, Gaiad, segundo Garcez, nos convida a estabelecer interlocuções, interrogar saberes e potencializar diálogos pela (nossa) Arte.

Completa o dossiê o artigo "Dança Contemporânea como prática qualificada e o bailarino como artesão do corpo" de autoria de Maíra Simões Claudino dos Santos. Ela nos convida à compreensão de prática qualificada para conceituar a dança contemporânea, a partir de discussões sobre habilidade, cinestesia, percepção, consciência do corpo, dentre outros conceitos, e diversos pesquisadores incluindo Tim Ingold, Richard Sennet e Ben Spatz. 
Ao longo do texto, a autora relaciona as práticas de dança à arte, à criação e à pedagogia enquanto também as identifica como práticas de vida. Técnica incorporada é compreendida "[...] enquanto mapas provisórios e contingentes do corpo" (p. 30). Práticas de dança são epistemológicas, a pesquisadora sugere, pois essa linguagem inventa modos de conhecer com dinâmicas e éticas particulares. Conhecimentos criados pelas práticas de dança potencializam criação de novas realidades.

Na seção de artigos, escrito a seis mãos por Ana Judite Oliveira Medeiros, Maria Lúcia Bastos Alves e Eduardo Lopes, "Canto do Sertão na Bachiana ำ4: uma perspectiva sociomusicológica" apresenta um estudo analítico que tem como objetivo investigar os recursos utilizados pelo compositor para construir uma representação do sertão nordestino em linguagem musical. Dessa forma, a música é potente para que elementos para além dela mesma sejam recriados e ressignificados.

A partir de um questionamento da visão dicotomizada que caracteriza as abordagens metodológicas na modernidade (qualitativa versus quantitativa, acadêmica versus aplicada), Celiane Camargo-Borges propõe em "Criatividade e imaginação: a pesquisa como transformação de mundo" uma perspectiva pragmática e contextual, fundamentada em uma epistemologia de pesquisa como prática social, em que o conceito de descoberta dá lugar ao de generatividade, tendo como foco a produção de "conhecimento local". Tal mudança de paradigma exige do pesquisador uma perspectiva coletiva e inclusiva, com a presença ativa dos participantes no processo e no contexto da pesquisa. Publicado originalmente em inglês, este artigo é uma tradução por Alexandre José Guimarães do capítulo "Creativity and Imagination: Research as World Making!", do livro Handbook of Arts-Based Research, organizado por Patricia Leavy, New York, Guilford Press, 2018.

O artigo de Sabina Couto Domingos Loureiro intitulado "A experiência da natureza como processo de inventividade" relata a investigação a respeito da imersão na natureza em relação com a criatividade e práticas artísticas, literatura, música, arquitetura e artes visuais, inventividade e resolução de problemas, elencando teóricos que defendem essa linha de pensamento. A autora apresenta documentos psicológicos e científicos no formato de ensaios, resultados de estudos, análises de entrevistas qualitativas e testes cognitivos a respeito dos efeitos da exposição prolongada em ambientes naturais com reduzida exposição humana, com e sem uso de tecnologia, além de estabelecer comparativos entre sujeitos participantes e intervenientes.

Fechando a seção, há um artigo cujo assunto é pouco explorado na literatura musicológica, "A performance musical das pessoas com deficiência visual" de Shirlei Escobar Tudissaki. Ela foca em aspectos de natureza técnica, cognitiva e sociológica envolvidos nessa prática. A autora apresenta, além de revisão bibliográfica interdisciplinar, informações obtidas de fontes primárias por meio de entrevistas e questionários. 
A coerência temática desse número é resultado das próprias submissões recebidas, as quais abordam de formas variadas a complexidade da Arte, incluindo pesquisas com perspectivas multidisciplinares. O corpus investigativo desse número da $A R J$ assim, potencializa a problematização e compreensão de vários aspectos que norteiam estudos na área. Cada artigo deixa sua contribuição para que possamos imaginar uma realidade diferente pós-pandemia.

Alba Pedreira Vieira (UFV; ABRACE)

Vera Lucia Didonet Thomaz (ANPAP)

Guilherme Sauerbronn (UDESC; ANPPOM)

Marcilio Vieira (UFRN; ANDA) 